AnUARIo De Estudios Medievales

49/2, julio-diciembre de 2019, pp. 619-643

ISSN 0066-5061

https://doi.org/10.3989/aem.2019.49.2.09

\title{
ORÍGENES Y DESARROLLO DE LA FIESTA LITÚRGICA DE LA VIRGEN MARÍA EN IBERIA*
}

\author{
THE ORIGINS AND DEVELOPMENT OF THE FEAST OF THE \\ VIRGIN MARY IN IBERIA
}

KATI IHNAT

Radboud Universiteit Nijmegen https://orcid.org/0000-0002-2356-6053

\begin{abstract}
Resumen: Se da por cierta una gran devoción mariana en la Iberia visigoda, especialmente por el establecimiento, en esa época, de una nueva celebración litúrgica en honor a la Virgen María. Sin embargo, el siglo VII conoció un progresivo desarrollo de liturgias marianas en diversas partes del Mediterráneo y de Europa occidental. En Roma se fundaron cuatro fiestas marianas a mediados del siglo VII, posiblemente con motivo del concilió de Letrán del año 649, en el que se declaró oficial la creencia en la perpetua virginidad de María. La presencia en Roma, alrededor de estas fechas, del obispo de Zaragoza, Tajón, hace suponer que el establecimiento de esta festividad mariana en Iberia pudo venir de fuera, tal como sugiere la legislación en torno a ella. Este estudio investiga los comienzos de esta conmemoración mariana con el fin de contextualizar el caso ibérico en el panorama devocional y teológico del momento.
\end{abstract}

Palabras claves: fiesta mariana; liturgia hispánica; España visigoda; Ildefonso de Toledo; Tajón de Zaragoza.

Abstract: There is a tendency to speak of a special devotion to the Virgin Mary in Visigothic Iberia, on the basis especially of the foundation of a new feast day in her honour. The seventh century nevertheless saw a general development of Marian liturgies in different parts of Mediterranean and Western Europe. In Rome alone, four Marian feasts were founded, probably around the mid-seventh century, and possibly linked to the Lateran Council of 649 where the doctrine of Mary's perpetual virginity was officially established. The presence in Rome of Taius, bishop of Zaragoza, raises the possibility that the idea of founding a new Marian feast in Iberia came from outside the Peninsula, as the very legislation founding the feast suggests. This study looks at the beginnings of Marian commemoration in order to integrate the Iberian case into a wider devotional and theological context. Keywords: Marian feast days; old Hispanic liturgy; Visigothic Spain; Ildefonsus of Toledo; Taius of Zaragoza.

La introducción en la tradición hispana de una nueva celebración litúrgica en honor a la Virgen María se ha interpretado frecuentemente como signo de una fuerte devoción mariana en Iberia durante época visigoda ${ }^{1}$. Fundada a mediados del siglo VII, esta festividad fue una de las más importantes

\footnotetext{
*Agradezco la ayuda del equipo del proyecto "Old Hispanic Office" subvencionado por la ERC en la Universidad de Bristol. También les doy las gracias a Charo Muro y a Josefina Rodríguez Arribas por su indispensable ayuda con el idioma.

${ }^{1}$ Por ejemplo, Bishop 1918; Ferrer 2008, p. 235; Fassler 2013, pp. 217-219.

Citation / Cómo citar este artículo: Ihnat, Kati (2019), Orígenes y desarrollo de la fiesta litúrgica de la Virgen María en Iberia, "Anuario de Estudios Medievales" 49/2, pp. 619-643. https://doi.org/10.3989/aem.2019.49.2.09

Copyright: (C) 2019 CSIC. Este es un artículo de acceso abierto distribuido bajo los términos de la licencia de uso y distribución Creative Commons Reconocimiento 4.0 Internacional (CC BY 4.0).
} 
del calendario viejo hispánico, tal como los manuscritos litúrgicos atestiguan. La novedad de la fiesta y de su liturgia se atribuye a los más destacados obispos hispanos de la época visigoda, sobre todo a Ildefonso de Toledo, quien escribió un tratado defendiendo la perpetua virginidad de María ${ }^{2}$. Sin embargo, el énfasis en la innovación hispana podría estar pasando por alto un complejo contexto histórico en el que tuvieron un papel destacado factores tanto internos como externos. En esta época el culto mariano ya se estaba desarrollando en otras zonas de Oriente y Occidente, lo que ciertamente pudo estimular su cristalización en Iberia $^{3}$.

Los estudios sobre los orígenes de esta festividad mariana en Iberia han tratado de manera muy general el desarrollo del culto mariano en otras regiones, al que no se ha reconocido sino una influencia superficial en el culto hispano ${ }^{4}$. El conocimiento de la fecha precisa en que la fiesta hispana fue establecida (656) nos permite sin embargo investigar influencias más directas y concretas. Cabe subrayar aquí que poco antes de la fundación de la festividad mariana, se había celebrado en Roma uno de los concilios de Letrán (649) en el que se estableció, so pena de anatema, la doctrina de la perpetua virginidad de María. No se conoce ningún obispo ibérico presente en este concilio, pero fue justo en estas fechas cuando llegó a Roma Tajón (ca. 600-683), más tarde nombrado obispo de Zaragoza. Su presencia en Roma sugiere su posible relación con la evolución litúrgica mariana que estaba entonces manifestándose en distintas regiones. En este estudio se pretende considerar la introducción de la fiesta mariana en la Iberia visigoda desde una perspectiva más amplia, que tenga en cuenta el contexto histórico, teológico y litúrgico de esta devoción, dentro y fuera de la Península Ibérica. Esto nos permitirá alcanzar una más completa comprensión de los factores externos que pudieron influir en el establecimiento de la festividad, sin perder de vista las tradiciones específicamente ibéricas dentro del desarrollo teológico y devocional mediterráneo ${ }^{5}$.

\footnotetext{
${ }^{2}$ Véanse los artículos reunidos en San Ildefonso de Toledo (†667) 2008, sobre todo Gironés 2008. Asimismo, Gironés 1964; García Rodríguez 1966, pp. 125-129; Ibáñez, Mendoza 1971; Ibáñez, Mendoza 1975; Garrido 1983; Ibáñez, Mendoza 1990.

${ }^{3}$ Intentos de identificar las primeras festividades marianas se encuentran en Jugie 1923; Botte 1933; Aldama 1965 y, más recientemente, en Fassler 2001; Shoemaker 2008b; 2016, pp. 178-194.

${ }^{4}$ Jordi Pinell indicó la posible presencia de paralelismos entre la conmemoración de María en Iberia y en otras zonas, pero sin entrar en detalles, y su obra (publicada después de su muerte) desafortunadamente carece de referencias, véase Pinell 1998, pp. 128-135. Véase también sobre esta cuestión, Garrido Boñano 1983, quien, trata de las tradiciones marianas orientales y occidentales, entre ellas la fiesta hispana, aunque no busca relaciones entre ellas.

${ }^{5} \mathrm{La}$ influencia romana en la liturgia hispana la propuso Janini 1965, pero no con relación a la fiesta mariana.
} 
Tanto la legislación como las fuentes litúrgicas muestran que la celebración de la Virgen María tenía un lugar destacado en la tradición litúrgica viejo-hispánica o más tarde mozárabe, practicada solamente en Iberia entre la época visigoda y finales del siglo $\mathrm{XI}^{6}$. La fiesta ibérica en honor a la Virgen fue establecida en el décimo concilio de Toledo, convocado por el rey godo Recesvinto el año 656. En el primer canon del concilio, los clérigos ibéricos se quejaron de que se celebraba a María en distintas fechas, y expresaron el deseo de unificar las celebraciones en una sola fiesta ${ }^{7}$. Decidieron entonces establecer una única fiesta mariana que se celebraría en todo el reino el 18 de diciembre, fecha que enlazaría con Navidad, una semana después ${ }^{8}$. Los legisladores no sólo buscaban establecer una fiesta específicamente mariana, sino que también querían elevarla al mismo rango de solemnidad que la fiesta del nacimiento de Jesús. En el canon conciliar se explica que la fiesta de María era igualmente la fiesta de la Encarnación, es decir, una conmemoración del momento de la concepción de Cristo en la Anunciación? ${ }^{9}$. Que el concilio fue un éxito se puede confirmar por el impacto de las decisiones conciliares en las fuentes litúrgicas copiadas en el siglo VIII y más tarde en los siglos X y $\mathrm{XI}^{10}$. En ellas se constata que el oficio mariano era uno de los más extensos en la tradición vieja hispánica, lo que interpretamos como un indicio de su importancia ${ }^{11}$.

${ }^{6}$ Una introducción a la tradición se encuentra en Pinell 1998 y, más recientemente, en Hornby, Maloy 2013. En ciertas parroquias de Toledo parece que se mantuvo (o se re-introdujo) la tradición vieja hispana después de que desapareciera en el resto de la Península. Sobre este complejo tema, véase Rojo 2018.

7 "Cur non festivitas gloriosae matris eius eadem observantia uno simul ubique die simulque habeatur honore? Invenitur etenim in multis Spaniae partibus huius sanctae virginis festum, non uno die per omnes annorum circulos agi”, can.1, Toledo X. Martínez, Rodríguez (eds.) 1992, pp. 518-519.

8 "Proinde ut de cetero quicquid est dubium, sit remotum, sollempnitas Dominicae matris die quintodecimo kalendarum ianuariarum omnimodo celebretur et nativitas Filii eius, Salvatoris nostri, die octavo kalendarum earundem, sicut mos est, sollemnis in omnibus habeatur." Ibidem, p. 521.

9 "Nam quid festum est matris nisi incarnatio Verbi? Cuius utique ita debet esse sollemne, sicut est et eiusdem nativitas Verbi." Ibidem.

${ }^{10}$ El manuscrito más antiguo es el oracional festivo: Verona, Biblioteca Capitolare Cod. 89 (s. VIII in.). Sobre la datación de este manuscrito, véase Rovalo 1966; Díaz 1971-1972; Díaz 1997. Los demás manuscritos son: Londres, British Library Add. MS 30852, (s. IX/X); Madrid, Real Academia de la Historia, Cod. 30, ff. 86-99v (s. X); Londres, British Library Add. MS 30844, ff. 33-50v (s. IX/X); León, Biblioteca de la Catedral, Cod. 8, ff. 56v-62 (s. X). Véanse también las ediciones (con las páginas refiriéndose al oficio mariano): Vives (ed.) 1946, pp. 6779; Gros 1984, pp. 152-155; Brou, Vives (eds.) 1953, pp. 67-76. Estudios de estos manuscritos se encuentran en: Zapke (ed.) 2007; Millares 1999.

${ }^{11}$ El oficio del amanecer en la tradición vieja hispánica, matutinum, estaba compuesto de unidades llamadas missae de cuatro cantos cada una: dos antífonas, un alleluiaticus y un responsorio. Cada canto se acompañaba de una oración propia. El número de estas variaba según 
El análisis de la liturgia mariana viejo-hispánica a la luz de la legislación conciliar permite constatar la influencia de la segunda en el desarrollo de la primera. El evangelio del día 18 de diciembre (fiesta de María) era el relato de la Anunciación (Lucas 1:26-38), texto que se encuentra también en los cantos de vísperas y de matutinum (oficio del amanecer) ${ }^{12}$. Esto confirma que la fiesta celebraba sobre todo el momento de la Anunciación, es decir, el momento de la Encarnación, tal como se legisló en Toledo. Es más, las resonancias intencionadamente creadas en la liturgia entre el relato de Lucas y los textos del Antiguo Testamento -sobre todo de los profetas Isaías, Ezequiel y Jeremías, pero también de las epithalamia bíblicas, Salmo 44 (45) y el Cantar de los Cantares- moldearon y enfatizaron una imagen de María como virgen y esposa perfecta de Dios que se unía a él en la Anunciación. Se destacaba sobre todo la virginidad de María, el tema principal de la liturgia. Los cantos y oraciones comparaban a María con las ciudades-fortaleza de Jerusalén (Ez 44:1-2) y Belén (Miq 5:2), con la torre del rebaño (Miq 4:8) y con el jardín cerrado u hortus conclusus (Cnt 4:12-13), refiriéndose a su integridad física. Como ya han señalado otros investigadores, esta virginidad se entendió siempre en un doble sentido: María fue virgen en la concepción de Jesús pero también permaneció virgen después del parto ${ }^{13}$. Los textos de la liturgia insisten una y otra vez sobre esta doble virginidad de María, ante partum et in partu.

Esta doble virginidad es también el tema central de un tratado que escribió Ildefonso, obispo de Toledo entre 657 y $667^{14}$. En su De virginitate beatae Mariae, Ildefonso se dirige a dos personajes herejes, Helvidio y Joviniano, a quienes se enfrentó Jerónimo en el siglo IV por pretender que María no siguió siendo virgen tras el nacimiento de Jesús. Según la mayoría de los historiadores, Ildefonso escribió el tratado para introducir la fiesta mariana del 18 de diciembre y puede que el tratado estuviese destinado a participar en la misma liturgia, ya que la mayoría de las versiones manuscritas -aunque más tardías- muestran divisiones internas separadas por rúbricas que se refieren a lectiones o missae. Estas rúbricas indican que el tratado fue utilizado

la solemnidad de la fiesta. La fiesta de María tenía siete missae, al igual que la Navidad. Sobre esta estructura, véase, sobre todo, Pinell 1954.

${ }^{12}$ Véase el índice de cantos en Ihnat 2016, pp. 75-85.

${ }^{13}$ Véase, sobre todo, Ibáñez, Mendoza 1971, pero también Aldama 1970 y Gironés 1964, pp. 56-57.

${ }^{14}$ Sobre el tratado, véase Ildefonso de Toledo, De virginitate, ed. Yarza Urquiola 2007; $\mathrm{Il}-$ defonso de Toledo, De virginitate, ed. Blanco García 1971; Braegelmann 1942; Rucquoi 1997 y el volumen dedicado a Ildefonso y su teología mariana en San Ildefonso de Toledo (†667); Balleros 1985; Del Valle 1998; Canal 1968. 
como lectura del oficio de matutinum ${ }^{15}$. La Vita de Ildefonso atribuye a este obispo la composición de parte del oficio matutinal, pero el fuerte carácter hagiográfico de esta obra hace dudar de dicha atribución ${ }^{16}$. Pese a todo, las resonancias temáticas y bíblicas entre el tratado y los textos litúrgicos podrían ser una indicación de que Ildefonso tuvo algo que ver con la composición litúrgica, aunque no fuera su autor ${ }^{17}$. Es posible que la devoción mariana de Ildefonso refleje también el contexto religioso y devocional en el que ejerció su papel de obispo, pues, según nos dan a conocer las actas del noveno concilio de Toledo en 655, la catedral de Toledo ya estaba dedicada a la Virgen María en esa época ${ }^{18}$. Más tarde, la festividad fue mencionada en las leyes de Ervigio (681) como una de las fiestas que incluso los judíos debían de observar guardando un día de descanso ${ }^{19}$. El apoyo real y episcopal que recibió la fiesta parece reflejar, por tanto, una corriente mariana importante en la cultura visigoda.

Con tales pruebas de la importancia de la fiesta en honor a la Virgen tanto en la legislación como en la liturgia propia, parece justificado afirmar que en la Iberia visigoda hubo una especial devoción a María, pero aún quedan cuestiones por aclarar en torno a la introducción de la fiesta mariana. Por ejemplo, cabe señalar que Ildefonso no era obispo de Toledo en 656 y ni siquiera estuvo presente en el décimo concilio. El editor más reciente del $D e$

\footnotetext{
${ }^{15}$ Estas están indicadas en las descripciones de manuscritos en la edición: Ildefonso de Toledo, De virginitate, ed. Yarza Urquiola 2007, pp. 91-120.

16 "Superueniente uero die Sanctae et semper uirginis Mariae, ante tres dies tribus diebus laetanias peregit, et missam suprascriptam, quae in eius laude decantaretur, perfecit, quae est septima." Yarza 2006, p. 320 con traducción p. 321. Algunos investigadores piensan que aquí la séptima misa/missa se refiere a la misa mariana (Pinell 1990). Otros (Férotin 1912, col. 16; De Bruyne 1913, p. 427; Braegelmann 1942, p. 154) creen que se refiere a las missae de maitines, mientras que Carmen García Rodríguez piensa que se refiere tan sólo a la séptima missa del oficio: García Rodríguez 1966, p. 132. La Vita data sin embargo del siglo XI según el editor más reciente, lo que no deja claro el asunto, Yarza 2006, pp. 283-285.

${ }^{17}$ Estas fueron subrayadas por Ibáñez, Mendoza 1971. Le atribuyen a Ildefonso la composición litúrgica, total o en parte: Brou 1950; Aldama 1970; Gironés 1964, p. 27. Duda de su composición Fassler 2013, p. 227.

18 "Dum canonicae definitionis edicto in Toletanam urbem pro peragendo concilio post diem kalendarum novembrium anno septimo Recesvinti gloriosi in basilicam sanctae Mariae virginis", Martínez, Rodríguez (eds.) 1992, pp. 490-491.

${ }^{19}$ Otras son la Navidad, Epifanía, Pascua, la Invención de la Cruz (i.e. el descubrimeinto de la santa cruz), Ascensión, Pentecostés y Domingos: "Dies tamen ipsi, qui ab isdem Iudeis sollicita devotione sunt observandi hii sunt: id est, festum virginis sancte Marie, quo gloriosa conceptione eiusdem genitricis Domini celebrator, item natalis Christi vel circumcisionis sive apparitionis sue dies, Pasca quoque sanctum vel dies sacratissimi octavarum, inventionis quoque cruces dominice festum necnon et ascensionis dominice diem vel Pentecosten seu etiam concurrentes per totum annum dies dominicos religiosa Christi fide venerabiles dies", Leyes de Ervigio, XII.3.6 en Zeumer (ed.) 1894, pp. 434-435; Linder 2000, pp. 294-296. Se confirmó esta ley en el duodécimo concilio de Toledo, en 681.
} 
virginitate, Valeriano Yarza Urquiola, propone que el tratado entero no fue escrito para la fiesta sino que es la adaptación de un tratado que Ildefonso elaboró originalmente para el octavo concilio de Toledo (653). La parte central del De virginitate se dirige a los judíos y, aunque trata de la concepción virginal, está más enfocado en la discusión de cuestiones cristológicas. Según Yarza Urquiola, las partes del tratado que defienden la virginidad perpetua fueron añadidas a la obra original sólo cuando se estableció la fiesta mariana tres años más tarde. Esta composición por etapas pondría en duda que el propio Ildefonso tomara la iniciativa de establecer la festividad movido por una profunda devoción a María ${ }^{20}$.

Es más, no hay una explicación adecuada para la urgencia a la hora de establecer una fiesta mariana, y de tal importancia, a mediados del siglo VII -tan urgente que fue tratada en el primer canon del concilio. La legislación del concilio parece mostrar que un ejemplo externo influyó en la instauración de la festividad:

Porque no parece que se hubiese establecido esta [fiesta] sin el ejemplo de las costumbres apropiadas que en diversas partes del mundo se observan, pues sabemos que en muchas iglesias muy alejadas de nosotros se sigue esta costumbre ${ }^{21}$.

Esta declaración menciona prácticas parecidas establecidas en otros lugares de la cristiandad que sirven de modelo para la nueva celebración en Iberia $^{22}$. ¿Es éste un mero argumento retórico o la clara indicación de una influencia externa en la liturgia y devoción en Iberia?

La primera indicación de que la conmemoración mariana en Iberia no se distinguía mucho de otras tradiciones en uso se encuentra en la legislación misma que estableció la fiesta mariana. Tal es la conclusión de Jordi Pinell, que sólo vamos a resumir aquí23 ${ }^{3}$. Cuando el texto del primer canon lamenta que antiguamente no se celebraba la festividad de María en el mismo día no se refería a que cada región la celebrara en fecha distinta, sino a que era una

\footnotetext{
${ }^{20}$ Esto contradice la tesis de que el tratado de Ildefonso inició la fiesta. Braegelmann 1942, p. 153.

21 "Quod tamen nec sine exemplo decentis moris qui per diversas mundi partes dinoscitur observari, videtur institui. In multis namque ecclesiis a nobis et spatio remotis et terris hic mos agnoscitur retineri.” Martínez, Rodríguez (eds.) 1992,p. 546. Esta traducción es más literal que la de Pinell, que me parece no capta el sentido original. Véase Pinell 1998, p. 135.

${ }^{22}$ No como dice Jugie, "suivant la coutume qui est en train de disparaître," lo que infiere de "Quod tamen nec sine exemplo decedentis moris". Jugie 1923,p. 146. La edición pone decentis moris, no indica que la tradición está desapareciendo, sino que se está adaptando al ejemplo de buenas (decentis) costumbres.

${ }^{23}$ Pinell 1998, pp. 129-135. Es posible que Pinell se basara en la misma conclusión de Jugie 1923, pp. 145-146, aunque la falta de referencias en la obra de Pinell no lo permite confirmar.
} 
festividad móvil ${ }^{24}$. La importancia de fijar la fecha (evitando que cayese en un día distinto cada año) tenía como objetivo establecer el valor sacramental del día. Los legisladores del décimo concilio de Toledo explicaron que la nueva fiesta debía estar ligada a la Navidad, siguiendo ejemplo de Pentecostés, que se celebra siempre cincuenta días después de Pascua, de modo que es necesario esperar ese tiempo para entrar en la "plenitud sacramental del misterio", tal como explica Pinell ${ }^{25}$. Una regla similar seguiría la Navidad y la Anunciación, dos festividades igualmente vinculadas. Dado que Navidad se celebra siempre el 25 de diciembre, la Anunciación también debería observar el intervalo fijo de días antes, vinculando la fiesta a una fecha del calendario. La fecha del 25 de marzo, que sería la más lógica para conmemorar el momento de la Anunciación, fue descartada por caer en Cuaresma, tiempo en el que no estaba permitido celebrar a los santo ${ }^{26}$. Esta explicación contenida dentro del mismo decreto nos indica que, antes del décimo concilio de Toledo, lo más probable es que la Anunciación se celebrara ya en Iberia como festividad móvil y dentro del periodo litúrgico de Adviento ${ }^{27}$.

La conmemoración mariana durante el periodo de Adviento parece haber tenido raíces orientales ${ }^{28}$. Historiadores como Stephen Shoemaker han encontrado pruebas de que el culto mariano empezó en el oriente medio y Bizancio mucho antes de lo que se venía pensando, como lo prueba la celebración litúrgica en época navideña de una festividad mariana ${ }^{29}$. La primera prueba la constituyen unas cartas de Atanasio de Alejandría, quien menciona lo que parece haber sido una conmemoración de la divina maternidad de María celebrada en Egipto en el año $370^{30}$. Los sermones del patriarca Proclus hacen suponer que el 26 de diciembre se celebraría también una fiesta mariana

\footnotetext{
${ }^{24}$ La legislación ha sido fuente de confusión para varios historiadores que han pensado que antes del décimo concilio se celebraba una fiesta mariana el 25 de marzo, y que se cambió la fecha a diciembre: Madoz 1952, p. 497. Otros dejan la cuestión sin resolver: García Rodríguez 1966, p. 129.

25 "hinc adventum Sancti Spiritus post resurrectionem Dei nisi exspectemus tempore definito dierum simul et numero, non possumus impleri eiusdem Spiritus dono, quoniam si caret plenitudinem numero, carere potest et mysterio sacramentum", Martínez, Rodríguez (eds.) 1992 , p. 518.

26 "Cum etiam et ipsam incarnationem Verbi non conveniat et tunc celebritatibus praedicari, quando constat idipsum Verbum post mortem carnis gloria resurrectionis attolli", ibidem, p. 520 .

${ }^{27}$ Esto lo articuló Pinell 1998, pp. 129-135.

${ }^{28}$ Sobre este tema véase Fassler 2001.

${ }^{29}$ Shoemaker 2016 en particular pp. 130-204; Shoemaker 2008b. Esto va en contra de lo que opinan muchos investigadores que sitúan los principios del culto tan solo en la segunda mitad del siglo V: Price 2004, 2007, 2008; Cameron 2004.

${ }^{30}$ Shoemaker 2016, pp. 178-180.
} 
en Constantinopla ya a principios del siglo $\mathrm{V}^{31}$. En la misma ciudad, el 18 de diciembre también se conmemoraba a María en la iglesia mariana de la Chalkoprateia ${ }^{32}$. En cambio, a principios del mismo siglo, en Jerusalén se celebraba la maternidad de María el 13 o 15 de agosto según varias fuentes ${ }^{33}$. Es tan solo en el siglo VI cuando parece haberse fijado la Anunciación en el 25 de marzo, apareciendo así mencionada en un sermón de Abraham de Éfeso $(\dagger c a .550)^{34}$. Resulta curiosa la coincidencia de fechas entre la fiesta de la Chalkoprateia y la fiesta mariana en Iberia, sobre todo considerando los frecuentísimos contactos entre los dos centros a lo largo de los siglos VI y VII, que se manifiestan en diferentes características de la liturgia bien documentadas $^{35}$. Cabe recordar asimismo que Leandro de Sevilla, obispo al que se atribuye un importante papel en el desarrollo litúrgico de la Iberia visigoda, pasó un tiempo en la corte bizantina ${ }^{36}$. Es posible que, durante su estancia, Leandro se inspirara en la devoción bizantina para presentar a María como ejemplo de virginidad en su De institutione virginum, obra dedicada a su hermana Florentina, y que, a su vez, esta obra llegara a influir en la liturgia mariana peninsu$\operatorname{lar}^{37}$. Sin embargo, la festividad en la Chalkoprateia celebraba sobre todo las reliquias marianas que se encontraban en esa iglesia y no la Anunciación, como era el caso en Iberia ${ }^{38}$.

La devoción mariana que se manifestó primero en el mundo oriental pudo también haber llegado a la Península Ibérica por otros caminos. En el siglo VII existían celebraciones marianas durante el periodo de Adviento en varias partes de Europa, como lo han demostrado Martin Jugie y, más recientemente, Margot Fassler ${ }^{39}$. En Roma, Milán, Ravena y en la Galia, se hacía una conmemoración de la concepción virginal, es decir, de la Anunciación, la semana previa a la Navidad: el último miércoles de Adviento (Témpora de Invierno) en Roma y el último domingo de Adviento en Milán, al igual que en la Galia ${ }^{40}$. Jugie dató estas conmemoraciones en el siglo $\mathrm{V}$ pero, como indica Fassler, las pruebas más antiguas en Roma son de mediados del siglo VII; sólo

${ }^{31}$ Ibidem, p. 180. Constas 2003, sobre todo Homilía I: pp. 128-156.

${ }^{32}$ Krausmueller 2011; Pentcheva 2006, p. 12; Shoemaker 2008a; Krueger 2014, p. 84.

${ }_{33}$ Véase Shoemaker 2016, pp. 181-184; Shoemaker 2001; Fassler 2001, pp. 46-60; Avner 2011.

${ }^{34}$ El sermón ha sido editado por Jugie 1922, pp. 442-447.

${ }^{35}$ Véase Fernández 2004; Janeras 1995.

${ }^{36}$ Isidoro de Sevilla, De Viris illustribus, ed. Codoñer Merino 1964, p.150.

${ }^{37}$ Ihnat 2016; Gómez 2004; Calvo 1990.

${ }^{38}$ Krausmueller 2011; Shoemaker 2008a.

${ }^{39}$ Jugie 1923; Fassler 2000.

${ }^{40}$ Jugie 1923, pp. 131-144. Véase también Moolan 1985, p. 270; Fassler 2000, en particular pp. $18-22$. 
en Ravena y en la Galia son anteriores ${ }^{41}$. La existencia de una fiesta móvil en Iberia, por tanto, tendría correlación con la misma manifestación en otros lugares de Europa, lo que ya hizo notar Pinell ${ }^{42}$.

Es posible detectar rasgos de esta antigua fiesta móvil en la liturgia mariana hispana reflejada en los manuscritos medievales. El oficio comparte ciertos textos de canto con el oficio de Adviento en la tradición francoromana $^{43}$. Por ejemplo, una antífona de la liturgia mariana contiene el mismo texto que un responsorio reservado al último domingo de Adviento en las primeras fuentes del oficio franco-romano: Virgo Israhel revertere ad civitates tuas usquequo dolens averteris generabis dominum salvatorem oblationem nobum in terram ambulabunt homines in salvatione ${ }^{44}$. El verso bíblico de base es aquí Jeremías 31:21-22, que ha sido adaptado de la versión de la Vulgata (revertere, virgo Israel, revertere ad civitates tuas istas. Usquequo deliciis dissolveris, filia vaga? quia creavit Dominus novum super terram: femina circumdabit virum $)^{45}$. Vemos el mismo fenómeno en un responsorio hispano que comparte el texto bíblico, también bastante modificado, con un responsorio franco-romano para el tercer domingo de Adviento: Bethlem civitas dei summi ex te prodiet/[exiet] dominator israhel et egressus eius sicut a principio dierum eternitatis et [magnificabitur in medio universae terrae et] pax erit in terram nostram quia veniet (combinación de Miq 5:2 y 5:5) ${ }^{46}$. En los dos ca-

\footnotetext{
${ }^{41}$ Las homilías de Pedro Crisólogo († 450), obispo de Rávena, parecen hablar de una fiesta mariana en Adviento, según Jugie 1923, pp. 146-149; Fassler 2000, pp. 20-21. También encontramos indicación de esta fiesta en el Rótulo de Ravena, un manuscrito litúrgico del siglo VII cuyo contenido data posiblemente de mucho antes. Véase sobre todo Benz 1967, pp. 341-342. Con respecto a la liturgia Galicana, hay dos misas marianas en el misal de Bobbio: Wilmart, Lowe, Wilson (eds.) 1991, pp. 37-39. La segunda es la de la Asunción: pp. 40-41. A esta última se refiere también Gregorio de Tours como fiesta celebrada el 18 de enero (Gregory de Tours 1988, p. 28). También aparece esta fiesta en el Martyrologium Hieronymiarum (Paris, Bibliothèque nationalde de France MS lat. 10837, f. 4r) y en el Leccionario de Luxeuil (Salmon 1953), cuyos contenidos datan del siglo VI. Véase a este respeto Hen 1995, pp. 44-48; 2004. La primera misa del misal de Bobbio es conocida sólo como Sanctae Mariae sollemnitate, y Jugie pensó que esta era la del Adviento. Aunque es verdad que los post-nomina se refieren a la maternidad de María, el evangelio es Lucas 10:38-42 (el relato de las hermanas Marta y María), no el de la Anunciación, lo que no deja claro cuál era esta fiesta ni cuándo se celebraba. Jugie 1923, p. 149.

${ }^{42}$ Pinell 1998, p. 130.

${ }^{43}$ La música, sin embargo es completamente distinta. Véase, como introducción a la tradición musical vieja hispánica, Hornby, Maloy 2013.

${ }^{44}$ Brou, Vives (eds.) 1953, 70; no. 7903 en Hesbert 1963, vol. 4 y accesible en la red: http://www.uni-regensburg.de/Fakultaeten/phil_Fak_I/Musikwissenschaft/cantus/[consulta: 10/12/2017].

${ }^{45}$ La diferencia entre el texto del canto y la Vulgata es demasiada como para pensar que el texto del canto es una versión de la Vetus Latina. Los libros de los profetas no forman parte de la edición de Ayuso (ed.) 1953-1962.

${ }^{46}$ Brou, Vives (eds.) 1953, p. 71, y no. 6254 en el Corpus antiphonalium officii: http://www. uni-regensburg.de/Fakultaeten/phil_Fak_I/Musikwissenschaft/cantus/ [consulta:10/12/2017].
} 
sos, los versos bíblicos han sido tan modificados que es difícil pensar que las similitudes sean casualidad. Tales ecos podrían indicar influencia hispana sobre el oficio franco-romano, ya que las primeras fuentes de este último son del siglo $\mathrm{IX}^{47}$. Sin embargo, podrían también atestiguar un intercambio cultural entre las dos regiones en relación al oficio de Adviento anterior a dicho siglo ${ }^{48}$

Jugie no dio a conocer estos paralelismos textuales entre las dos tradiciones litúrgicas. Aun así, la existencia de una festividad mariana celebrada en Roma en Adviento le pareció explicación suficiente de la mención, en el canon del concilio Toledano, de iglesias lejanas que ya celebraban una fiesta mariana $^{49}$. Dado que la fiesta móvil existía tanto en Iberia como en Roma o Milán antes de la celebración del décimo concilio toledano, el que éste mencione otras fiestas móviles como modelos para instaurar el 18 de diciembre no puede explicar la decisión conciliar. Parece más plausible que los legisladores estuvieran refiriéndose a festividades marianas que se celebraban en fechas fijas.

En el siglo VII tuvo lugar en Roma un importante desarrollo de la conmemoración litúrgica de María. Fue durante este siglo que se adoptaron las cuatro fiestas litúrgicas propiamente marianas: la Purificación (2 febrero), la Anunciación (25 marzo), la Asunción (15 agosto), y la Natividad (8 septiembre). No ha podido determinarse en qué preciso momento estas se celebraron por vez primera ${ }^{50}$. Aunque su aparición suele datarse en la segunda mitad del siglo VII, algunos investigadores sostienen que hubo una festividad anterior que se celebraba el primero de enero, o que la Purificación ya se conmemoraba con una procesión en el siglo $\mathrm{VI}^{51}$. La primera prueba segura de la presencia de estas fiestas en el calendario romano se encuentra en el Sacramentario gelasiano, que data de entre 628 y $715^{52}$. Como el evangeliario de tipo P-I

\footnotetext{
${ }^{47}$ Este es el antifonario de Compiègne, sobre el cual véase: Jonsson 2000.

${ }^{48}$ Algunos de estos intercambios litúrgicos, especialmente los referentes a la misa, fueron tratados por Janini 1965.

${ }^{49}$ Jugie intentó explicar que con el 18 de diciembre, la legislación refería la fecha en la que caía la fiesta móvil en las tradiciones romano-milanesas cuando la Navidad se celebraba en domingo (la festividad del 18, siete días antes, también caía en domingo). Jugie 1923, p. 146.

${ }^{50}$ La fecha habitual es la segunda mitad del siglo VII: Chavasse (ed.) 1958, pp. 375-402; Maître 1996 p. 47; Jeffery 1995, p. 217; Palazzo, Johansson 1996, pp.17-18; Bradshaw, Johnson 2011 , p. 212.

${ }^{51}$ La existencia de una festividad mariana el 1 de enero en Roma fue propuesta inicialmente por Botte 1933, y repetida por Chavasse (ed.) 1958, vol. 1, pp. 651-656; Frénaud 1949; Maître 1996, p. 46; Palazzo, Johansson 1996, p. 16. Se ha demostrado que no hay ninguna prueba de que esta festividad fuera mariana, en particular por Guilmard 1994. La fecha de la primera festividad de la Purificación ha sido propuesta por MacGregor 2008, situada a mediados del siglo VII por Dyer 2011, pp. 39-40.

${ }^{52}$ Mohlberg (ed.) 1918, pp. 12, 103, 167-168, 178. Este manuscrito es una copia del siglo VIII de un texto anterior. Sobre este manuscrito, véase Chavasse 1958. Una introducción útil de los sacramentarios se encuentra en Fassler 2000, pp. 22-27.
} 
(ca. 645) no las menciona, este intervalo se reduce en algunos años ${ }^{53}$. Por otra parte, la presencia de las cuatro en los sacramentarios de Padua y de Trento demuestra que estas se celebraban en varias iglesias de Roma a principios de la década de $680^{54}$. Al comparar los sacramentarios de Adriano y de Padua, James McKinnon propuso que el papa Sergio I (687-701), de origen sirio, implantó tres de las fiestas en la liturgia papal (Anunciación, Asunción, y Natividad), y que fue durante su pontificado cuando fueron compuestos los cantos propios de las misas de estas festividades; para entonces ya se celebraría también la Purificación ${ }^{55}$. El Liber Pontificalis atribuye al mismo papa el establecimiento de una procesión en cada una de las fiestas marianas ${ }^{56}$. Sin embargo, el Liber Pontificalis nos dice tan sólo que Sergio estableció una serie de procesiones marianas, no las fiestas en $s^{157}$. Desgraciadamente, las dificultades en reconstruir la liturgia romana primitiva a partir de manuscritos más tardíos limita la posibilidad de llegar a conclusiones firmes acerca de la conmemoración mariana ${ }^{58}$. Tampoco es posible establecer hasta qué punto la influencia bizantina fue decisiva para esta evolución ${ }^{59}$. Lo único que podemos concluir aquí es que, entre $c a .645$ y $c a .680$, las fiestas marianas probablemente empezaron a celebrarse en Roma.

Una especial circunstancia que pudo favorecer la implantación de las festividades marianas en Roma es que el concilio de Letrán (649), convocado por el papa Teodoro I (642-49) y supervisado por Martín I (649-655)

${ }^{53}$ Discutido por McKinnon 2000, pp. 165-167.

${ }^{54}$ Dyer 2011,p. 41.

${ }_{55}$ McKinnon 2000, pp. 182-185, basado en Deshusses 1979, p. 128 para el Hadrianum, y pp. 635-636 para el Paduensis.

56 "Constituit autem ut diebus Adnuntiationis Domini, Dormitionis et Nativitatis sanctae dei Genitricis semperque virginis Mariae ac sancti Symeonis, quod Hypapante Gregi appellant, letania exeat sancto Hadriano et ad sanctam Mariam populus occurrat", Duchesne (ed.) 1886, p. 376; Davis (ed.) 1989, p. 87.

${ }^{57}$ Como ha notado Dyer 2011, p. 40, en contra de McKinnon 2000, pp. 186-187. Duchesne, editor del Liber Pontificalis, indica que, bajo Sergio I, no se habla de las fiestas como novedades, lo que toma como signo de que las fiestas fueron adoptadas en un momento desconocido del siglo VII; Duchesne (ed.) 1886, p. 381; Frénaud 1949 pensaba que la fiesta de la Hypapante ya existía a mediados del siglo. 2000

${ }^{58}$ Es un problema que no suele reconocerse, aunque lo señalan Guilmard 1994 y Fassler

${ }^{59} \mathrm{La}$ influencia bizantina sobre la devoción mariana en Roma ha sido puesta en duda por Thomas Noble (Noble 2014, p. 84). Aunque acepta las fechas propuestas por Chavasse para la adopción progresiva de las festividades marianas a lo largo del siglo VII, propone que el culto mariano fue débil en Roma antes del siglo VIII, y que se desarrolló en ese momento en competencia con Bizancio. Esto no quiere decir que en el siglo VII las fiestas no existieran ni que sus raíces fueran orientales, algo que es difícil negar. 
tras la muerte de aquél, tuvo como objeto condenar la doctrina monotelista ${ }^{60}$. El problema de si Cristo tuvo una voluntad (divina) o dos (divina y humana) culminó en un debate con repercusiones tanto políticas como teológicas. Teodoro era un vigoroso partidario del dogma que mantiene dos naturalezas y dos voluntades en Cristo (el ditelismo establecido en el concilio de Calcedonia de 451) y se saltó todas las convenciones cuando convocó él mismo el concilio del 649 sin el permiso del emperador, que era defensor del monotelismo (posición teológica que sostenía para Cristo una sola voluntad). Dejando a un lado los problemas políticos que suscitó la decisión del papa Teodoro de convocar un concilio al margen de la voluntad imperial, en el tercer canon de este concilio el papa Martín I pronunció el dogma de la perpetua virginidad de María:

Si quis secundum sanctos patres non confitetur proprie et secundum veritatem dei genetricem sanctam semperque virginem et inmaculatam Mariam, utpote ipsum deum verbum specialiter et veraciter qui a deo patre ante omnia saecula natus est in ultimis saeculorum absque semine conceptam ex spiritu sancto et incorruptibiliter eam genuisse, indissolubile permanente et post partum eiusdem virginitate, condemnatus sit $^{61}$.

Se formula aquí por vez primera la doctrina de la perpetua virginidad decretada por decisión conciliar y confirmada como posición oficial de la Iglesia universal, según la carta encíclica que acompaña los cánones ${ }^{62}$.

Cabe preguntarse qué tiene que ver la virginidad perpetua de María con el debate sobre la voluntad/voluntades de Cristo. Michael Hurley concluye que el dogma de la virginidad de María fue un movimiento fundamental a favor del ditelismo cristiano, pues suponía que no pudo haber conflicto en la persona de Cristo en el momento de la Encarnación ${ }^{63}$. El hecho de que María fuese virgen permitía que las dos voluntades de Cristo (humana y divina) estuviesen en perfecta armonía. Sin contacto sexual, la concepción de Cristo por la Virgen se hizo sin transmisión del pecado original, lo que implica que

${ }^{60}$ Introducciones útiles al concilio, sus participantes y sus temas y objetivos se encuentran en: Herrin 1989, pp. 252-255; Ekonomou 2007, pp. 113-157; Cubitt 2009.

${ }_{61}$ "Si alguien no confiesa adecuadamente y conforme a la verdad, siguiendo a los santos padres, que María es la santa madre de Dios, virgen perpetua e inmaculada por cuanto concibió, en época reciente, a Dios mismo, único y verdadero, el Verbo engendrado del Padre antes de los siglos, al que concibió del Espíritu Santo sin semilla humana y sin corrupción de su virginidad, que permaneció intacta después del parto, sea condenado", Riedinger (ed.) 1984, p. 371, con traducción griega en p. 370.

${ }^{62} \mathrm{Ibidem}$, pp. 404-421. Aunque investigadores como Ekonomou afirman que el concilio fue más bien provincial (Ekonomou 2007, p. 140), otros mantienen que las intenciones de los líderes fueron promulgar los cánones con validez universal, como los de un concilio ecuménico: Hurley 1961, pp. 220-223; Cubitt 2009, en particular pp. 142-44.

${ }^{63}$ Hurley 1961. 
la voluntad humana de Cristo nunca se opuso a su voluntad divina. La voluntad humana de Cristo sería entonces por sí sumisa a su voluntad divina, como lo eran las de Adán y Eva antes de caer en el pecado original ${ }^{64}$. De esta manera quedaría solucionado el problema de las dos voluntades según las dos naturalezas de Cristo sin recurso a la posición monotelista. Y aunque no lo precisa Hurley, el hecho de que María fuese siempre virgen, que su virginidad no desapareciera ni durante el parto ni después, dejaba fuera de duda que su cuerpo -del que Jesús tomó forma- era completamente casto, sin contaminación alguna de pecado. La virginidad perpetua de María sería así el fulcro del argumento anti-monotelista. Esto podría también dar base a la teoría de que Teodoro estableció las cuatro fiestas marianas, como algunos han sugerido ${ }^{65}$.

Ciento cinco obispos estuvieron presentes en el concilio de Letrán del año 649 en el que se estableció bajo amenaza de anatema la virginidad perpetua de María ${ }^{66}$. Cierto es que ninguno de estos clérigos procedía de la Península Ibérica. En realidad no se trataba propiamente de un concilio ecuménico, ya que la convocatoria no vino del emperador. La participación en el concilio estuvo limitada a clérigos italianos y a un grupo de monjes griegos que vinieron con Máximo el Confesor, uno de los principales actores en el debate ${ }^{67}$. Con todo, sabemos que un clérigo ibérico estuvo en Roma el año 649 o poco después, aunque no participó en el concilio, Tajón, abad y más tarde obispo de Zaragoza ${ }^{68}$. En una carta dirigida al obispo de Toledo, Eugenio II, Tajón describe cómo, durante un viaje a Roma, copió obras de Gregorio Magno que no estaban disponibles en Iberia ${ }^{69}$. En un relato más tardío, la Crónica de 754,

\footnotetext{
${ }^{64}$ Véase sobre todo la discusión en ibidem, pp. 231-233.

${ }^{65}$ Primero, Baumstark, Heiming, Mohlberg 1967, p. 156, y referido en Dyer 2011, pp. 39-40; McKinnon 2000, pp. 107 y 185.

${ }^{66}$ Este número lo encontramos en Davis (ed.) 1989, p. 69, y también en las listas de participantes del concilio, referidas por Riedinger (ed.) 1984, pp. 2-7, 31-35, 111-115, 177-181, 247-251.

${ }^{67} \mathrm{La}$ importancia de Máximo, sobre todo para la teología discutida en el tercer canon, se trata en Hurley 1961, pp. 232-233, y, más generalmente, en Ekonomou 2007, pp. 134-137.

${ }^{68}$ Véase Martin 2010, pp. 196-200, y sobre el viaje a Roma, Madoz 1951; Robles 1971, pp. 22-23. Se ha deducido la fecha del viaje (entre 649 y 650) de una carta que escribió Braulio $(† 651)$ tras el regreso de Tajón: "peto ita Christus cursum propositi tui efficiat gloriosum ut mihi Codices sancti papae Gregorii inexpositos, qui necdum in Hispania erant tuoque studio et sudore de Roma huc sunt delati ad transcribendum ocius mittas...", Ep. 42, Riesco 1975, p. 154.

69 "Igitur cum Romae positus ejusdem [Gregorii], quae in Hispaniis deerant, volumina sedulus vestigator perquirerem, inventaque propria manu transcriberem, tantaque dulcedo verborum animum meum inaestimabili suavitate mulceret, speciale quiddam in eadem sine cujuspiam perspexi comparatione potissimum”, Tajón de Zaragoza, Epistula ad Eugenium, ed. Díaz 1979, pp. 342-346, 1. 71-74. Sobre esta carta, véase también Miguel 2010. Otra obra de Gregorio que pudo conocer Tajón en Roma es un comentario sobre el Cantar de los Cantares, del que produjo su propia Explicatio, según Palacios 1980. La mayoría de los historiadores piensan que Tajón fue en busca de las obras, pero Díaz 1979, pp. 333-334, indica que Tajón no nos dice que ese
} 
se explica que Tajón estuvo en Roma porque quería consultar específicamente una de las obras de Gregorio Magno, Moralia in Job, pero tan solo recibió ayuda del papa Martín I tras hacerle saber que el difunto papa Gregorio le había revelado en una visión nocturna dónde se encontraba el libro ${ }^{70}$. Retenemos el dato histórico de la presencia de Tajón en Roma alrededor de la fecha del concilio de Letrán sin tener que aceptar necesariamente en su sentido literal la versión hagiográfica de los hechos ${ }^{71}$. Tajón no dice nada sobre el concilio en las pocas cartas suyas que se conservan ${ }^{72}$, pero es difícil imaginar su estancia en Roma sin que mantuviera contacto con alguno de los clérigos participantes y sin que se enterara de los debates que se estaban entablando en él acerca de la naturaleza de Cristo - que, como hemos visto arriba, se relacionaban con la virginidad perpetua de María.

Es por tanto posible que este clérigo hispano estuviera expuesto en Roma a un nuevo movimiento de devoción y doctrina mariana. También es posible que Tajón fuera testigo de los comienzos de la celebración litúrgica mariana, que estaría ya en desarrollo a mediados de siglo con la adopción de las cuatro festividades marianas. De la misma manera, Tajón pudo asimismo entrar en contacto con los monjes griegos que estuvieron presentes en el concilio de Letrán, los cuales traerían consigo información sobre el culto mariano de sus iglesias orientales (en Palestina y en Bizancio). De esta forma Tajón pudo haberse familiarizado con fiestas propiamente marianas celebradas en fechas fijas que eran distintas de la fiesta móvil que se seguía en Iberia. Tajón pudo también enterarse entonces de la decisión de establecer el dogma de la virginidad perpetua de María como uno de los argumentos contra el monotelismo. Se da por hecho que la doctrina de la virginidad perpetua en sí ya era bien conocida; en Iberia hablaron de ella Gregorio de Elvira ( $† 392)$, Baquiario $(† c a .425)$, y también Isidoro de Sevilla ( $† 636)$ en su De fide catholica ${ }^{73}$. Cabe

fuera su objetivo inicial, sino que, una vez allí, decidió copiarlas. Puede que Tajón fuera con la intención de asistir al concilio, aunque esto es improbable, pues sólo se trataba de un concilio provincial.

${ }^{70}$ Wolf (ed.) 1990, pp. 119-120.

${ }^{71}$ Es importante notar que la obra Moralia era ya bien conocida en Iberia antes del viaje de Tajón, como nos lo recuerdan Madoz 1951, p. 351; Robles 1971, p. 23. Martin 2010, p. 197 propone que Tajón estaba copiando en Roma una versión de Moralia de mejor calidad.

${ }^{72}$ Además de la carta dirigida a Eugenio II, obispo de Toledo, hay otra que sirve de prefacio a las Sententiae dirigida a Quírico, obispo de Barcelona: Tajón de Zaragoza, Sententiae, ed. Migne, PL 80:727-729.

${ }^{73}$ Los debates más agrios sobre esta cuestión tuvieron lugar a finales del siglo IV, cuando Atanasio, Ambrosio y Jerónimo atacaron a los que negaban el dogma de la virginidad perpetua, como Helvidio y Joviniano. Shoemaker 2016, pp. 169-172. Isidoro dice: "Quo testimonio sanctam Mariam et virginem concepisse et virginem permansisse confitetur." Libro I, Cap. X, Isidoro de Sevilla , PL 83:470. Sobre los teólogos ibéricos, véase Llamas 1990; y sobre Isidoro, más concretamente, Bengoechea 1990, pp. 114-115; Díez 1990, en especial p. 173. 
suponer que el concilio no hizo sino ratificar una doctrina ya generalmente aceptada. Sin embargo, el hecho de que se adoptase el año 656 en Iberia una nueva fiesta celebrando la virginidad perpetua poco tiempo después de que Tajón volviera de Roma, parece indicar una posible conexión entre ambos hechos $^{74}$. Tajón no estuvo en el décimo concilio de Toledo, sino en el octavo (653) y en el noveno (655), en los que pudo haber discusiones iniciales sobre la posibilidad de introducir una nueva fiesta litúrgica. Eugenio II, interlocutor de Tajón, estuvo por su parte en el décimo concilio de Toledo y, como obispo de Toledo, jugó en él un papel importante ${ }^{75}$. Puede sugerirse que, en este contexto, Ildefonso se sintió motivado para modificar su anterior tratado sobre la Encarnación y adaptarlo a un nuevo tema, la virginidad perpetua de María, el centro de una nueva festividad.

Para concluir, los hechos relevantes analizados en este estudio y que fundamentan la tesis en él presentada (a saber, que el ejemplo romano pudo influir en Iberia en cuanto a la fundación de la fiesta mariana) son:

1. La muy posible fundación de las cuatro fiestas marianas a mediados del siglo VII en Roma.

2. El concilio de Letrán en el que fue establecido el dogma de la virginidad perpetua el año 649 .

3. La presencia de Tajón en Roma por esas fechas.

4. La fundación el año 656, tras el regreso de Tajón a Iberia, de una nueva festividad que celebraba la virginidad perpetua de María y que se presentó como fundamentada en modelos ajenos (según el texto conciliar).

La coincidencia temporal de estos eventos podría ser muy significativa de cómo y por qué terminó estableciéndose la festividad mariana fija en Iberia durante este siglo. No es necesario concluir que la liturgia vieja hispánica tomara ejemplo directamente de la de Roma, pues la fiesta hispana del 18 de diciembre no tiene paralelo directo. Una rica tradición de celebración litúrgica mariana en el mundo oriental se combinó en Iberia con prácticas marianas procedentes de distintas partes de Europa y del Mediterráneo: primero la festividad de la Anunciación en el Adviento (Rávena, Roma, Milán, Iberia y la Galia), y después la adopción de festividades

\footnotetext{
${ }^{74}$ La posible influencia que pudo tener el Concilio de Letrán en la nueva festividad mariana en Iberia se menciona, pero sin elaboración, en Ibáñez, Mendoza 1975, p. 85.

${ }^{75}$ Es posible que problemas con el rey Recesvinto impidiera la participación de Tajón, ya obispo de Zaragoza (desde 651), como fue el caso de Ildefonso (Ildefonso de Toledo, De virginitate, ed. Yarza Urquiola 2007, pp. 22-23).
} 
específicamente marianas (empezando con la Asunción en la Galia, seguido de las cuatro festividades marianas en Roma, y finalmente la festividad del 18 de diciembre en Iberia), todas siguiendo seguramente, hasta cierto punto, el modelo bizantino.

En este contexto, la fundación de la fiesta mariana en Iberia no es un hecho aislado, sino que parece formar parte de un movimiento pan-europeo en los siglos VI y VII, lo que no excluye el papel que en su implantación y desarrollo pudieran tener factores específica y exclusivamente hispanos. Es conocido el deseo de los clérigos visigodos de definir una teología unitaria y clara sobre la segunda persona de la Trinidad, para contrarrestar, por un lado, la memoria de la herejía arriana, tan fuerte en la Península, y, por otro, la temida apostasía de judíos a la fuerza bautizados. Instaurar una festividad mariana con una liturgia original era una manera de definir con toda claridad una cristología ortodoxa frente a los cristianos disidentes ${ }^{76}$. La innovación y originalidad autóctona hispana, que pudo influir en otras regiones, no excluyen absolutamente la influencia externa, al contrario. El presente estudio señala la necesidad de tener en cuenta el contacto entre regiones Mediterráneas y la influencia mutua entre ellas, vehiculada frecuentemente a través de individuos concretos, y el impacto de estos contactos en la cultura religiosa y devocional del período. Desde la perspectiva mediterránea, la Península Ibérica fue siempre mucho menos periférica y participó, una veces más visiblemente que otras, de la cultura devocional mediterránea y europea.

\section{BIBLIOGRAFÍA CITADA}

\section{FUENTES PRIMARIAS}

Baumstark, Anton; Heiming, Odilo; Mohlberg, Leo Cunibert (1967), Die älteste erreichbare Gestalt des Liber sacramentorum anni circuli der Römischen Kirche: (Cod. Pad. D47, f. 11r-100r), Münster, Aschendorff.

Brou, Louis; Vives, José (eds.) (1953), Antifonario visigótico mozárabe de la catedral de León, vol. 1, Barcelona, CSIC. (Monumenta Hispaniae Sacra: serie litúrgica; 5).

\footnotetext{
${ }^{76}$ Sobre la importancia de la cristología dentro de la cultura teológica de la Iberia visigótica, sobre todo en las obras de Ildefonso de Toledo e Isidoro de Sevilla, véanse Domínguez 1971, pp. 297-299; Martínez 2008; Drews 2006, p. 171. Sobre la motivación antijudía, véase Ihnat 2017. Sobre el deseo visigodo de unidad teológica frente a la amenaza de cisma, véanse sobre todo Stocking 2002; Lester 2017, p. 242.
} 
Chavasse, Antoine (ed.) (1958), Le sacramentaire gélasien (Vat. Reg. 316), sacramentaire presbytéral en usage dans les titres romains au VII siècle. Bibliothèque de Théologie. Série IV, París, Desclée \& Cie.

Davis, Raymond (tr.) (1989), The Book of Pontiffs (Liber Pontificalis), Liverpool, Liverpool University Press.

Duchesne, Louis, (ed.) (1886), Le Liber pontificalis; texte, introduction et commentaire, París, Ernest Thorn.

Gregorio de Tours, Glory of the Martyrs, trans. Raymond van Dam, Liverpool, Liverpool University Press, 1988.

Hesbert, Renate-Jean (1963), Corpus antiphonalium officii, Roma, Herder.

Ildefonso de Toledo, La virginidad perpetua de Santa María. Historia de su tradición manuscrita, texto y comentario gramatical y estilístico, ed. y trad. Vicente Blanco García, Madrid, La Editorial Católica, 1971.

Ildefonso de Toledo, De Virginitate Sanctae Mariae; De Cognitione Baptismi; De Itinere Deserti, ed. Valeriano Yarza Urquiola, Turnhout, Brepols, 2007 (Corpus Christianorum, Series Latina; 114).

Isidoro de Sevilla, El De viris illustribus de Isidoro de Sevilla. Estudio y edición crítica. ed. Carmen Codoñer Merino, Salamanca, Ediciones Universidad Salamanca, 1964.

Isidoro de Sevilla, De fide catholica contra Iudaeos, ed. Jacques Paul Migne, Patrologia Latina (PL), 1841-1855, vol. 83, cols. 449-538.

Martínez Díez, Gonzalo; Rodríguez Barbero, Félix (eds.) (1992), La colección canónica hispana. V. Concilios hispanos: segunda parte, Madrid, Consejo Superior de Investigaciones Científicas.

Mohlberg, Leo Cunibert, (ed.) (1918), Das fränkische Sacramentarium Gelasianum in alamannischer Überlieferung (Codex Sangall. No. 348) St. Galler Sakramentar-Forschungen, Münster, Aschendorff.

Riesco Terrero, Luis (1975), Epistolario de San Braulio. Introducción, edición crítica y traducción, Sevilla, Universidad de Sevilla.

Salmon, Pierre (1953), Le lectionnaire de Luxeuil (Paris, Ms. lat. 9427). Tome I: édition et étude comparative, contribution à l'histoire de la Vulgate et de la liturgie en France au temps des Mérovingiens, Roma, Abbaye Saint-Jérôme - Libreria Vaticana.

Tajón de Zaragoza, Epistula ad Eugenium Toletanum episcopum, ed. Jacques Paul Migne, Patrologia Latina (PL), 1841-1855, vol. 80, cols. 723-728. Tajón de Zaragoza, Sententiae, ed. Jacques Paul Migne, Patrologia Latina (PL), 1841-1855, vol. 80, cols. 727-990.

Vives, José (ed.) (1946), Oracional visigótico, Barcelona, Consejo Superior de Investigaciones Científicas - Biblioteca Balmes (Monumenta Hispaniae Sacra: serie litúrgica; 1). 
Zeumer, Karl, (ed.) (1894), Leges visigothorum antiquiores, Fontes juris germanici in usum scholarum ex monumentis Germaniae historicis separatim edidit 4, Hannover, Hahn.

\section{ESTUDIOS}

Aldama, José Antonio de (1970), Valoración teológica de la literatura litúrgica hispana, en La Patrología toledano-visigoda: XXVII semana española de teología, Toledo 25-29 de septiembre de 1967, Madrid, CSIC, Patronato Menéndez Pelayo, pp. 137-157.

Aldama, José Antonio de (1965), La primera fiesta litúrgica de Nuestra Señora, "Estudios eclesiásticos" 40, pp. 43-59.

Avner, Rina (2011), The Initial Tradition of the Theotokos at the Kathisma: Earliest Celebrations and the Calendar, en Brubaker, Leslie; Cunningham, Mary (eds.), The Cult of the Mother of God in Byzantium, Farnham, Ashgate, pp. 9-29.

Ayuso Marazuela, Teófilo, (ed.) (1953-1962), La Vetus Latina Hispana: Origen, dependencia, derivaciones, valor e influjo universal, 5 vols., Madrid, CSIC.

Balleros Mateos, Juana (1985), El tratado De virginitate Sanctae Mariae de San Ildefonso de Toledo. Estudios sobre el estilo sinonímico latino, Toledo, Estudio Teológico de San IIldefonso. Seminario Conciliar.

Bengoechea, Ismael (1990), San Isidoro de Sevilla, figura señera de la Mariología española, en Doctrina y Piedad Mariana en Torno al III Concilio de Toledo, Toledo, Sociedad Mariologica Española, pp. 107-123 (Estudios Marianos; 55).

Benz, Suitbert (1967), Der Rotulus von Ravenna nach seiner Herkunft und seiner Bedeutung für die Liturgiegeschichte, Münster, Aschendorff.

Bishop, Edmund (1918), Spanish Symptoms, en Bishop, Edmund (ed.), Liturgica Historica: Papers on the Liturgy and Religious Life of the Western Church, Oxford, Clarendon Press, pp. 165-202.

Botte, Bernard (1933), La première fête mariale de la liturgie romaine, "Ephemerides liturgicae" 47, pp. 425-430.

Bradshaw, Paul F; Johnson, Maxwell E. (2011), The Origins of Feasts, Fasts and Seasons in Early Christianity, Collegeville, MN, Liturgical Press.

Braegelmann, Athanasius (1942), The Life and Writings of Saint Ildefonsus of Toledo, Washington, Catholic University of America (tesis doctoral). Brou, Louis (1950), Les plus anciennes prières liturgiques adressées à la Vierge en Occident, "Hispania Sacra" 3, pp. 371-381. 
Calvo Moralejo, Gaspar (1990), Presencia de la Virgen María en la Regla de San Leandro, en Doctrina y Piedad Mariana en Torno al III Concilio de Toledo, Toledo, Sociedad Mariológica Española, pp. 175-189 (Estudios Marianos; 55).

Cameron, Averil (2004), The Cult of the Virgin in Late Antiquity: Religious Development and Myth-making, en Swanson, Robert N. (ed.), The Church and Mary, Woodbridge, Boydell and Brewer, pp. 1-21 (Studies in Church History; 39).

Canal, José María (1968), Tradición manuscrita y ediciones de la obra de san Hildefonso de Virginitate Sanctae Mariae, "Revista española de teología" 28, pp. 51-75.

Constas, Nicholas (2003), Proclus of Constantinople and the Cult of the Virgin in Late Antiquity: Homilies 1-5, Texts and Translations, Leiden, Brill.

Cubitt, Catherine (2009), The Lateran Council of 649 as an Ecumenical Council, en Price, Richard M.; Whitby, Mary (eds.), Chalcedon in Context: Church Councils 400-700, Liverpool, Liverpool University Press, pp. 133-147.

De Bruyne, Donatien (1913), De l'origine de quelques textes liturgiques mozarabes, "Revue bénédictine" 30, pp. 421-436.

del Valle Rodriguez, Carlos (1998), El Tratado de la virginidad perpetua de Santa Maria de San Ildefonso de Toledo, en del Valle Rodríguez, Carlos (ed.), La controversia Judeocristiana en España (Desde los orígenes hasta el siglo XIII), Madrid, CSIC, pp. 115-118.

Deshusses, Jean (1979), Le sacramentaire grégorien: ses principales formes d'après les plus anciens manuscrits, París, Editions universitaires.

Díaz y Díaz, Manuel (1971-1972), La fecha de implantación del oracional festivo, "Boletín arqueológico órgano de la Real Sociedad Arqueológica Tarraconense" 71/2, pp. 216-243.

Díaz y Díaz, Manuel (1979), Libros y librerías en la Rioja altomedieval, Logroño, Servicio de Cultura de la Diputación Provincial.

Díaz y Díaz, Manuel (1997), Consideraciones sobre el oracional visigótico de Verona, en Billanovich, Giuseppe; Frasso, Giuseppe (eds.), Petrarca Verona e l'Europa: Atti del Convegno internazionale di studi, Pádua, Antenore, pp. 13-29.

Díez Merino, Luis (1990), Interpretación mariológica de citas bíblicas en San Isidoro de Sevilla, en Doctrina y Piedad Mariana en Torno al III Concilio de Toledo, Salamanca, Sociedad Mariológica Española, pp. 125-173 (Estudios Marianos; 55).

Domínguez del Val, Ursicino (1971), Personalidad y herencia literaria de S. Ildefonso de Toledo, "Revista española de teología" 31, pp. 137-166. 
Drews, Wolfram (2006), The Unknown Neighbour: The Jew in the Thought of Isidore of Seville, Leiden, Brill.

Dyer, Joseph (2011), The Celebration of Candlemas in Medieval Rome, en Buckley, Ann; Cyrus, Cynthia J. (eds.), Music, Dance and Society: Medieval and Renaissance Studies in Memory of Ingrid G. Brainard, Kalamazoo, Medieval Institute Publications, pp. 37-70.

Ekonomou, Andrew J. (2007), Byzantine Rome and the Greek Popes: Eastern Influences on Rome and the Papacy from Gregory the Great to Zacharias, A.D. 590-752, Lanham, Lexington Books.

Fassler, Margot (2000), Sermons, Sacramentaries, and Early Sources for the Office in the Latin West: The Example of Advent, en Fassler, Margot; Baltzer, Ruth A. (eds.), The Divine Office in the Latin Middle Ages, Oxford, Oxford University Press, pp. 15-47.

Fassler, Margot (2001), The first Marian Feast in Constantinople and Jerusalem: Chant Texts, Readings and Homiletic Literature, en Jeffery, Peter (ed.), The Study of Medieval Chant: Paths and Bridges, East and West: in honor of Kenneth Levy, Woodbridge, Boydell Press, pp. 25-87.

Fassler, Margot (2013), Mary in Seventh-century Spain: the Mass Liturgy of Dec. 18, en Fernández de la Cuesta, Ismael; Álvarez Martínez, Rosario; Llorens Martín, Ana (eds.), El canto mozárabe y su entorno. Estudios sobre la música de la liturgia viejo hispánica, Madrid, Sociedad Española de Musicología, pp. 217-236.

Fernández Jiménez, Francisco María (2004), Influencias y contactos entre la liturgia hispana y las liturgias orientales byzantina, alejandrina y antioquena, en Pérez Martín, Inmaculada; Bádenas de la Peña, Pedro (eds.), Bizancio y la Península Ibérica: de la antigüedad tardía a la edad moderna, Madrid, CSIC, pp. 165-176.

Férotin, Marius (1912), Le liber mozarabicus sacramentorum et les manuscrits mozarabes, París, Firmin-Didot.

Ferrer, Juan Miguel (2008), San Ildefonso de Toledo. Liturgia y mariología, en San Ildefonso de Toledo (†667) y los rasgos de la Mariología Hispana, Salamanca, Sociedad Mariológica Española 74, pp. 213-236 (Estudios Marianos; 74).

Frénaud, Grégoire (1949), Le culte de Notre Dame dans l'ancienne liturgie latine, en du Manoir, Hubert (ed.), Maria: Études sur la Sainte Vierge, París, Beauchesne, pp. 157-211.

García Rodríguez, Carmen (1966), El culto de los santos en la España Romana y Visigoda, Madrid, CSIC, Instituto Enrique Flórez.

Garrido Boñano, Manuel (1983), La primera fiesta litúrgica en honor de la Virgen María, "Ephemerides mariologicae" 33, pp. 279-291. 
Gironés Guillem, Gonzalo (1964), La Virgen María en la liturgia mozárabe, "Separata de los Anales del Seminario de Valencia" 4, pp. 9-163.

Gironés Guillem, Gonzalo (2008), La Virgen María en la liturgia visigótica, en San Ildefonso de Toledo (†667) y los rasgos de la Mariología Hispana, Salamanca, Sociedad Mariológica Española, pp. 237-245 (Estudios Marianos; 74).

Gómez Cabo, Antonio (2004), La Virgen María en Leandro de Sevilla, "Carthaginensia" 20, pp. 57-108.

Gros i Pujol, Miquel dels Sants (1984), El liber misticus de San Millán de la Cogolla, "Miscellànea litúrgica catalana" 3, pp. 111-224.

Guilmard, Jacques-Marie (1994), Une antique fête mariale au ler janvier dans la ville de Rome? "Ecclesia orans" 11, pp. 26-67.

Hen, Yitzhak (1995), Culture and Religion in Merovingian Gaul: AD 481-751, Leiden, Brill.

Hen, Yitzhak (2004), The Liturgy of the Bobbio Missal, en Hen, Yitzhak; Meens, Rob (eds.), The Bobbio Missal: Liturgy and Religious Culture in Merovingian Gaul, Cambridge, Cambridge University Press, pp. 140-153.

Herrin, Judith (1989), The Formation of Christendom, Princeton, NJ, Princeton University Press.

Hornby, Emma; Maloy, Rebecca (2013), Music and Meaning in Old Hispanic Lenten Chants, Woodbridge, The Boydell Press.

Hurley, Michael (1961), Born Incorruptibly: The Third Canon of the Lateran Council (A.D. 649), "Heythrop Journal" 2, pp. 216-226.

Ibañez, Javier; Mendoza, Fernando (1971), María madre de Jesús y madre de la Iglesia en la perspectiva teológica de la liturgia visigótica, "Scripta theologica: revista de la Facultad de Teología de la Universidad de Navarra" 3, pp. 343-421.

Ibañez, Javier; Mendoza, Fernando (1975), María en la liturgia hispana, Pamplona, Ediciones Universidad de Navarra.

Ibañez, Javier; Mendoza, Fernando (1990), La liturgia hispana y su contenido mariológico, Doctrina y Piedad Mariana en Torno al III Concilio de Toledo, Salamanca, Sociedad Mariológica Española, pp. 69-106 (Estudios Marianos; 55).

Ihnat, Kati (2016), Mary as Bride in the Old Hispanic Office: Liturgical and Theological Trends, "Mediaeval Studies" 78, pp. 65-123.

Ihnat, Kati (2017), Liturgy as Apostasy. Marian Commemoration and the Jews in Visigothic Iberia, "Early Medieval Europe" 25, pp. 1-23.

Janeras, Sebastià (1995), Elements orientals en la litúrgica visigótica, "Miscel·lania litúrgica catalana" 6, pp. 93-127. 
Janini, José (1965), Roma y Toledo: nueva problemática de la liturgia visigótica, en Rivera Recio, Juan Francisco (ed.), Estudios sobre la liturgia mozárabe, Toledo, Diputación Provincial, pp. 33-53.

Jeffery, Peter (1995), Rome and Jerusalem: From Oral Tradition to Written Repertory in Two Ancient Liturgical Centers, en Boone, Graeme M. (ed.), Essays on Medieval Music: In Honor of David G. Hughes, Cambridge, MA, Harvard University Press, pp. 207-247.

Jonsson, Ritva (2000), The Antiphoner of Compiègne, Paris BNF lat. 17436, en Fassler, Margot; Baltzer, Ruth A. (eds.), The Divine Office in the Latin Middle Ages, Oxford, Oxford University Press, pp. 147-178.

Jugie, Martin (1922), Homélies mariales byzantines. Textes grecs édités et traduits en latin, París, Firmin-Didot, vol. I, pp. 427-580 (Patrologia Orientalis; 16/3).

Jugie, Martin (1923), La première fête mariale en Orient et en Occident, l'Avent primitif, "Échos d'Orient" 22, pp. 129-152.

Krausmueller, Dirk (2011), Making the Most of Mary: The Cult of the Virgin in the Chalkoprateia from Late Antiquity to the Tenth Century, en Brubaker, Leslie; Cunningham, Mary (eds.), The Cult of the Mother of God in Byzantium, Aldershot, Ashgate, pp. 219-245.

Krueger, Derek (2014), Liturgical Subjects: Christian Ritual, Biblical Narrative and the Formation of the Self in Byzantium, Filadelfia, University of Pennsylvania Press.

Lester, Molly (2017), The Word as lived. The practice of orthodoxy in early medieval Iberia, c. 500-711, Princeton NJ, Princeton University (tesis doctoral).

Linder, Amnon (2000), The Jews in the legal sources of the early Middle Ages, Detroit, Wayne State University Press.

Llamas, Enrique (1990), La doctrina mariana en España antes del Concilio III de Toledo (a.589) en Doctrina y Piedad Mariana en Torno al III Concilio de Toledo, Toledo, Sociedad Mariologica Española, pp. 29-50 (Estudios Marianos; 55).

MacGregor, Alistair (2008), Candlemas: A Festival of Roman Origin, en Maunder, Chris (ed.), Origins of the Cult of the Virgin Mary, Londres, Burnst and Oates, pp. 137-153.

Madoz, José (1951), Tajón de Zaragoza y su viaje a Roma, en Mélanges Joseph de Ghellinck, S. J., II. Moyen Âge, Gembloux, Éditions J. Duculot, pp. 345-360 (Museum Lessianum; 14).

Madoz, José (1952), S. Ildefonso de Toledo, "Estudios eclesiásticos" 26, pp. 467-505.

Maître, Claire (1996), Du culte marial a la celebration des vierges. A propos de la psalmodie de matines, en Iogna-Prat, Dominique; Palazzo, 
Éric; Russo, Daniel (eds.), Marie: Le culte de la vierge dans la société médiévale, París, Beauchesne, pp. 45-64.

Martín, José Carlos (2010), Tajón de Zaragoza, en Codoñer Merino (ed.), La Hispania visigótica y mozárabe. Dos épocas en su literatura, Salamanca, Ediciones Universidad de Salamanca, pp. 196-200.

Martínez Sierra, Alejandro (2008), San Ildefonso de Toledo: fundamentos para una cristología, en San Ildefonso de Toledo (†667) y los rasgos de la Mariología Hispana, Salamanca, Sociedad Mariológica Española, pp. 131-140 (Estudios marianos; 74).

McKinnon, James (2000), The Advent Project: The later seventh-century creation of the Roman Mass proper, Berkeley, University of California Press.

Miguel Franco, Ruth (2010), Ecos del Epistularium de Braulio de Zaragoza en la carta prefacio de Tajón de Zaragoza a Eugenio de Toledo (CPL 1267) en los Moralia in Job, "Lemir" 14, pp. 289-300.

Millares Carlo, Agustín, et al. (1999), Corpus de códices visigóticos, Las Palmas de Gran Canaria, Universidad Nacional de Educación a Distancia, Centro Asociado de Las Palmas de Gran Canaria - Gobierno de Canarias.

Moolan, John (1985), The Period of Annunciation: Nativity in the East Syrian Calendar, its Background and Place in the Liturgical Year, Roma, Pontifical Oriental Institute of Religious Studies.

Noble, Thomas F.X. (2014), Greek Popes: Yes or No, and Did it Matter? en Fischer, Andreas; Wood, Ian (eds.), Western Perspectives on the Mediterranean: Cultural Transfer in Late Antiquity and the Early middle Ages, 400-800 AD, Londres, Bloomsbury, pp. 77-86.

Palacios Martín, Ángela (1980), Tajón de Zaragoza y la Explicatio in Cantica Canticorum, "Anuario de estudios filológios" 3, pp. 115-127.

Palazzo, Éric; Johansson, Ann-Katrin Andrews (1996). Jalons liturgiques pour une histoire du culte de la Vierge dans l'Occident latin (Vt$X I^{e}$ siècle), en Iogna-Prat, Dominique; Palazzo, Éric; Russo, Daniel (eds.), Marie: Le culte de la Vierge dans la société médiévale, París, Beauchesne, pp. 15-43.

Pentcheva, Bissera (2006), Icons and Power: The Mother of God in Byzantium, University Park, PA, Pennsylvania State University Press.

Pinell, Jordi (1954), Las missae: grupos de cantos y oraciones en el oficio de a antigua liturgia hispana, "Archivos leoneses" 8, pp. 145-185.

Pinell, Jordi (1990), Consecrabis Domino. Una obra litúrgica insigne de san Ildefonso de Toledo, Toledo, Estudio Teológico de San Ildefonso.

Pinell, Jordi (1998), Liturgia Hispánica, Barcelona, Centre de Pastoral Litúrgica. 
Price, Richard M. (2004), Marian Piety and the Nestorian Controversy, en Swanson, Robert N. (ed.), The Church and Mary, Woodbridge, Boydell and Brewer, pp. 31-38 (Church Studies; 39).

Price, Richard M. (2007), Theotokos: The Title and its Significance in Doctrine and Devotion, en Boss, Sarah (ed.), Mary: The Complete Resource, Oxford, Oxford University Press, pp. 56-74.

Price, Richard M. (2008), The Theotokos and the Council of Ephesus, en Maunder, Chris (ed.), The Origins of the Cult of the Virgin Mary, Londres, Burns and Oates, pp. 89-103.

Riedinger, Rudolf (ed.) (1984), Concilium Lateranense a. 649 celebratum. Acta Conciliorum Oecumenicorum, Series Secunda, Berlin, De Gruyter.

Robles Carcedo, Laureano (1971), Tajón de Zaragoza, continuador de Isidoro, "Saitibi" 21, pp. 19-25.

Rojo Carrillo, Raquel (2018), Old Hispanic Chant Manuscripts of Toledo: Testimonies of a Local or of a Wider Tradition? en Beale-Rivaya, Yasmine; Busic, Jason (eds.), A Companion to Medieval Toledo: Shared Common Spaces, Leiden, Brill.

Rovalo, Pedro (1966), Temporal y santoral en el Adviento visigodo, "Hispania Sacra" 19/38, pp. 243-320.

Rucquoi, Adeline (1997), Ildéfonse de Tolède et son traité sur la virginité de Marie, "Etudes Mariales" 57, pp. 105-125.

San Ildefonso de Toledo (†667) y los rasgos de la Mariología Hispana (2008), Salamanca, Sociedad Mariológica Española (Estudios Marianos; 74).

Shoemaker, Stephen (2001), The (Re?)Discovery of the Kathisma Church and the Cult of the Virgin in Late Antique Palestine, "Maria: A Journal of Marian Studies" 2, pp. 21-72.

Shoemaker, Stephen (2008a), The Cult of Fashion: The earliest Life of the Virgin and Constantinople's Marian relics, "Dunbarton Oak Papers" 62, pp. 53-74.

Shoemaker, Stephen (2008b), Marian Liturgies and Devotion in early Christianity, en Boss, Sarah J. (ed.), Mary: The Complete Resource, Oxford, Oxford University Press, pp. 130-145.

Shoemaker, Stephen (2016), Mary in Early Christian Faith and Devotion, New Haven, CT, Yale University Press.

Stocking, Rachel (2002), Bishops, Councils and Consensus in the Visigothic Kingdom, 589-633, Ann Arbor, University of Michigan Press.

Wilmart, André; Lowe, Elias A.; Wilson, Harold A. (eds.) (1991), The Bobbio Missal: a Gallican Mass-Book (MS. Paris. Lat. 13246), Notes and Studies, Woodbridge, Boydell Press (Henry Bradshaw Society; 58). 
Wolf, Kenneth B. (trad.) (1990), Conquerors and Chroniclers of Early Medieval Spain. Translated Texts for Historians, Liverpool, Liverpool University Press.

Yarza Urquiola, Valeriano (2006), La Vita vel Gesta Sancti Ildefonsi de Ps. Eladio: estudio, edición crítica y traducción, "Veleia" 23, pp. 279-325.

Zapke, Susana (ed.) (2007), Hispania Vetus: Musical-Liturgical Manuscripts from Visigothic Origins to the Franco Roman Transition $\left(9^{\text {th }}-12^{\text {th }}\right.$ Centuries), Bilbao, Fundación BBVA.

Fecha de recepción del artículo: diciembre 2017

Fecha de aceptación y versión final: octubre 2018 